\title{
Imigração e colonização japonesa no Brasil - um resumo
}

\author{
Aline Midori de Moraes Tanaka - FAPERGS - BIC
}

\section{Introdução}

A imigração japonesa teve início no Brasil quando um grupo formado por 781 japoneses contratados para trabalhar em lavouras de café e mais 12 livres $^{1}$ que chegaram em Santos, no navio Kasato-Maru, em 18 de junho de 1908. As razões que motivaram a vinda de imigrantes japoneses para o Brasil tiveram inicio ainda no século anterior. Em 1868, o governo japonês inicia uma série de reformas (a restauração Meiji) que visavam a modernização e a inserção do país na economia mundial e uma das medidas tomadas foi o incentivo à emigração. Outra razão para incentivar a emigração é o fato de que já naquela época os japoneses se preocupavam com o problema do crescimento demográfico e procuravam novos lugares para viver. As primeiras relações do Japão com o Brasil surgem nessa época. Em 1895 é firmado o Tratado de Amizade, Comércio e Navegação entre os dois paúses porém, sem nenhuma menção quanto à vinda de imigrantes. O Brasil só vai se interessar pela mão de obra japonesa em 1902, quando o governo italiano restringe a vinda de novos imigrantes. Por outro lado o Brasil começa a se tornar uma boa saída para o plano de expansão japonês quando em outros países, como no Canadá o nos EUA, são criadas barreiras para dificultar a enrrada e a permanência de japoneses em seus territórios ${ }^{2}$. Além disso, o incentivo à emigração foi uma das soluções encontradas pelo governo do arquipélago para diminuir a miséria e o alto índice de desemprego que se registrava no país na época, fruto da própria restauração Meiji .

'Enquanto SAITO, Hiroshi, "O japonês no Brasil : esrudo de mobilidade e fixação", São Paulo : Ed, Sociologia e Política, 1961, fala de 12 livres, FIANDA, Fxâncisco "O imigrante japones - história da sua vida no Brasil", São Paulo, ed. T.A. Queiroz, Editor, LTDA,p.4 menciona "10 espontâneos e outros".

${ }^{2}$ Bem antes do Brasil, japoneses haviam emigrado ao Hawai e à Iha de Guam, aa China. Mais tarde outras levas foram para os Estados Unidos, Canadá, México e Peru. 


\section{Os primeiros imigrantes}

O destino dos primeiros imigrantes japoneses no Brasil foram as lavouras de café no interior de São Paulo. As experiências anteriores com imigrantes europeus no Brasil e, por outro lado, as experiências japonesas em outros países fizeram com que se firmasse uma série de acordos para garantir o bem-estar dos imigrantes e também o investimento dos fazendeiros brasileiros. Procurou-se regulamentar bem a vinda e permanência dos japoneses e, portanto, ficou estabelecido que os imigrantes deveriam formar famílias de no mínimo três pessoas pois assim se acreditava que a possibilidade de abandono do trabalho ficava reduzida. Os trabalhadores vinham com conrrato de trabalho de, no minimo, dois anos e a passagem seria em parte subsidiada pelo governo de São Paulo para depois ser deduzida dos salários dos trabalhadores.

Essa primeira fase da imigração japonesa no Brasil ficou marcada pelo seu caráter experimenral e seus efeitos eram completamente desconhecidos por ambas as partes. De um lado, tanto o governo japonês quanto os próprios imigrantes eram otimistas quanto ao trabalho no Brasil enquanto que, entre os brasileiros, havia uma resistência quanto à vinda e possivel permanência de imigrantes não brancos. Todavia, da parte dos japoneses, não havia interesse na permanência no Brasil, pois viam o trabalho no Brasil apenas como uma possibilidade de juntar dinheiro rapidamente e voltar para o Japão um pouco mais rico. No entanto, para os imigrantes, as condições de trabalho encontradas fotam desanimadoras e as dificuldades de adapração foram grandes, visto que eram fisicamente muito diferentes, tinham dificuldades com a comunicação e também não se acostumavam com a comida brasileira. Além disso, não conheciam direito o trabalho na lavoura, que era pesado demais e as condições de moradia e saneamento eram por demais precátias, não foram raras as epidemias entre a comunidade. Outro problema foram as crises econômicas que fizeram com que muitas das promessas de dinheiro fácil não fossem cumpridas gerando revoltas entre os imigrantes. ${ }^{3}$

Ainda assim, o interesse do governo japonês pelo Brasil se mantinha e a falta de oportunidades no Japão empurravam multidões que sonhavam com as terras brasileiras. Por ourro lado, os fazendeiros brasileiros continuam precisando de mão de obra. Portanto, mesmo com um breve corte nos subsidios paulistas, em 1914, os esforços das empresas de imigração japonesas não cessaram. Dessa forma, em 1916, as empresas de imigração conseguem nova concessão que prevê a entrada de 4 a 5 mil colonos por ano durante os próximos 4 ou 5 anos a partir de 1917. Nesse mesmo ano, ogoverno japonês cria a KKKK (Kaigai Kogyo Kabusbiki Kaisha), empresa estatal que rrabalharia no recrutamento de trabalhadores nos mesmos moldes em que empresas privadas já vinham trabalhando. A criação dessa empresa inicia um processo de mudanças no modelo de imigração japonês que culmina com o corte definitivo dos subsidios brasileiros. Durante esse primeito período de imigração chegam ao Brasil 31.414 imigrantes ${ }^{4}$.

${ }^{3}$ HANDA, Op. Cit.

${ }^{4}$ SAKURAI, Célia, "Imigração Japonesa para o Brasil: un exemplo de imigração tutelada. Fazer a América - A imigração em massa para a América Latina”, São Paulo: Editora da Universidade de São Paulo, 1999. 


\section{A imigração tutelada}

O fim da ajuda brasileira não caracterizou uma diminuição do fluxo de japoneses para o Brasil, pelo contrário, o período que durou de 1924 a 1941 foi o que registrou o maior número de entradas $\left(137.572^{5}\right)$. Isso se explica devido a situação do Japão no cenário internacional que vinha expandindo a sua indústria e dominando territórios pela a Ásia originando urn clima de tensão com Grã-Bretanha, Estados Unidos e França por causa da concorrência econômica. Toda essa situação faz com que em diversos países criem-se batreiras para dificultar a entrada de japoneses alegando-se dificuldade de adaptação e aculturação. $O$ Brasil é o único país que não cria barreiras explícitas. Além disso, a emigração era uma boa oportunidade de mandar os camponeses pobres para fora do Japão. Por isso, mesmo com o fim dos incentivos brasileiros, tem-se início a fase em que a imigração passou a ser tutelada. O governo japonês passou a financiar, organizar e a divulgar a emigração através da KKKK. A partir de 1925, o Brasil passa a set visto pelos japoneses não apenas como destino para rrabalhadores, mas também como mercado para investimento. Por isso esse periodo ficou caracterizado pela formação de colônias com caráter capitalistas. Além da KKKK, financiou a compra de terras em regiões despovoadas e também a construção de estradas, hospitais e escolas criando toda a infra-estrutura para a fixação das famílias também houve investimentos da iniciativa privada. Essas colônias funcionavam como cooperativas e se tornaram uma das principais características da colonização japonesa. As empresas japonesas passaram a investir em loteamento e colonização, reunindo os novos imigrantes e aqueles já residentes no País. Como exemplo pode-se citar as colônias de Tietê (hoje Pereira Barreto), Bastos e Alianças, além de Três Bartas (atual Assaí, Norte do Paraná), fundadas pela Cooperativa de Colonização do Brasil Ltda., popularmente conhecida por Bratac). Esse período de imigração tutelada também caracterizou-se pela ascensão social dos imigrantes japoneses. O plano de colonização do governo japonês propiciou a aquisição de terras e, dessa forma, o imigrante não precisava mais trabalhar como assalariado nas lavouras de café. Nesse período, mesmo que o desejo dos imigrantes fosse o retorno rápido ao Japão, o governo japonês criou incentivos para fixação, tanto para os imigrantes novos quanto para os que já estavam no Brasil. Também a impossibilidade de entiquecimento rápido fez com que os imigrantes desistissem da idéia de mandar dinheiro às famílias no Japão e começassem a investir no Brasil. O início da década de trinta coincidiu também com o preenchimento do período mínimo de estada dos imigrantes remanescentes da primeira fase nas fazendas de café. Com o dinheiro das suas economias, os imigranres, incentivados pelos seus representantes, deslocaram-se para o interior do estado de São Paulo. As empresas de colonização acompanharam as mudanças no cenário brasileiro após a crise de 1929. Prestando atenção na construção das estradas de ferro, os agentes japoneses vêem a possibilidade de aquisição de terras em torno dessas estradas a baixo custo. Esse caráter pioneiro foi responsável em boa parte pelo processo de ascensão social dos imigrantes japoneses. Além das colônias do governo e das formadas por

${ }^{5}$ Idem. Ibidem. 
incentivos privados, surgem também aquelas formadas em grande parte por trabalhadores que se instalaram ainda no período inicial e que agora procuravam autonomia económica. Esses núcleos, apesar do apoio das entidades japonesas, desenvolvem por iniciativa própria e sem um planejamento prévio e, por isso, seu desenvolvimento foi mais lento e modesto. Todo esse quadro fez da década de 30 um grande momento na história da imigração japonesa no Brasil que só teve fim devido a eminência da segunda guerra mundial. Foi nesse periodo também que houve uma grande deslocação dos imigrantes pelo território brasileiro. Nessa década os japoneses vão para Goiás, Amazonas, Pará e Paraná.

\section{No pós-guetra}

A partir de 1942 e dutante quase uma década, houve uma ruptura na história migratória. Entretanto, mesmo com o fim da fase dos grandes contingentes para o Brasil, esse período foi bastante importante para o desenvolvimento das colônias. $O$ corte de comunicação, ainda que temporário, dos imigrantes com o Japão fez com esses começassem a se reorganizar melhor dentro do Brasil. Foi um periodo onde se operou uma mudança na menralidade dos imigrados fazendo com que, finalmente, diante da situação que se encontravam, desis tissem da imigração temporária e começassem a pensar em investimentos a longo prazo no Brasil. Essas mudanças de atitude geratam alguns distúrbios dentro do próprio grupo ${ }^{6}$ mas que não foram suficientes para abalar profundamente a sua estrutura. A partir de 1946, acontece a retomada da publicação de jornais em língua estrangeira e são lançados vátios jornais em lingua japonesa.

Na década de cinqüenta, são retomadas as entradas de japoneses no país. Em abril de 1952 é celebrado o tratado de paz entre Brasil e Japão e as relações diplomáticas entre os dois países são retomadas. Em 1953, chega o primeiro navio trazendo os imigrantes do pósguerra, 54 ao todo. A partir de então, os japoneses não param mais de chegar e instalam-se por todo o país, do Amazonas até o RS. As décadas de 60 e 70 são decisivas na fixação e integração definitivas dos japoneses no Brasil.

\section{No RS}

Embora os imigrantes japoneses tenham chegado ao Brasil em 1908, só em 1955 eles chegaram oficialmente à Região Sul. Os primeiros imigrantes japoneses no Rio Grande do Sul vieram na década de vinte por conta própria, isto é, independentes da tutela do governo japonês. Na década seguinte, iniciaram-se as primeiras tentarivas de uma imigração

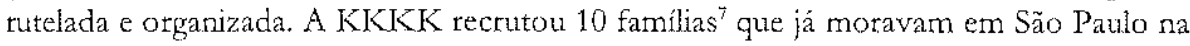
rentativa de fundar uma colônia em Santa Rosa. Porém, com a eminência da Segunda Guerra, o governo brasileiro proíbe que estrangeiros possuam terras em um raio de 150 quilometros

\footnotetext{
"SAITO, Op. Cit.

7 FLORES, Moacyr, "Japoneses no Rio Grande do Sul", Revista Veritas, a. 77, tomo XX, 1975.
} 
a partir da fronteira ${ }^{8}$. Os imigrantes que abandonaram esta colônia dispersaram-se pelo estado e por Santa Catarina. Na segunda metade da década de cinqüienta, teve início a corrente imigtatória direta. Em agosto de 1956, chegaram no porto de Rio Grande um grupo de imigrantes composto por 23 rapazes solteiros. A idéia era constituir uma cooperativa agrícola que acabou não se realizando'. No início, os rapazes ficavam em granjas nos arredores de Porto Alegre, mas depois se dispersaram pelo estado. Assim como esses casos, outras tentativas de se organizar uma colônia sob tutela fracassaram fazendo com que os imigrantes se espalhassem pelo estado. As dificuldades apareciam sempre ou por falta de organização dos agentes japoneses ou pelo não cumprimento das promessas dos proprietários de terras brasileiros.

A primeira tentativa de se formar um núcleo organizado de imigrantes bem sucedida foi a Colônia de Ivoti, situada à $50 \mathrm{~km}$ ao norte de Porto Alegre. Ela foi fundada em 1967, com o apoio da atual JICA (Agência Internacional de Cooperação do Japão). Hoje, abriga $40^{16}$ familias, que se dedicam principalmente à fruticultura, floxicultura e horticultura. Depois dela, a Colônia de Itati, que hoje possui 10 familias no ramo da horticultura, mas que foi fundada em 1968 com o apoio da atual JICA e fica à $170 \mathrm{~km}$ a nordeste de Porto Alegre. A outra colônia no estado é a Colônia de Itápuã, fundada em 1975 também com o apoio da atual JICA, situa-se a $70 \mathrm{~km}$ ao sul de Porto. Alegre, com 18 familias dedicadas à horticultura (principalmente ao cultivo de alface) ${ }^{11}$.

\section{BIBLIOGRAFLA}

DOLL, Johannes, Et Alii. A Colônia Japonesa de Itotiz primeiro relato de una pesquisa interdisciplinar. In: Revista da Faculdade de Direito da Universidade Federal do Rio Grande do Sul. Porto Alegre:

FLORES, Moacyr, Japoneses no Rio Grande do Sul, Revista Veritas, n. 77, tomo XX. Porto Alegre: LdPUC, 1975.

HANDA, Tomoo, O Imigrante Japonês - História de Sua Vida no Brasil, T.A. Queiroz/ Centro de Estudos Nipo-Brasileiros. São Paulo, 1987.

SAITO, Hiroshi, O japontês no Brasil: estudo de mobilidade e fixacão. São Paulo: Ed. Sociologia a politica, 1961.

SAKURAI, Célia, Imigraçâo Japonesa para o Brasil; um exemplo de imigrafäo tutelada. Fazer a América - A imigrafãa em massa para a América L atina, São Paulo: Editora da Universidade de São Paulo, 1999

VÁRIOS. Caminho dos imigrantes japoneses-Brasil- século 20, ed. União Nikkei Ltda, 2000.

8 "Caminho dos imigrantes japoneses - Brasil - século 20", ed. União Nikkei Ltda, 2000.

"I Iem. Ibidem.

10 DOLL, Johannes. "A Colônia Japonesa de Ivoti : primeiro relato de uma pesquisa interdisciplinar". In: Revista da Faculdade de Direito da Universidade Feleral do Rio Grande do Sul. Porto Alegre N. esp. (set. 2002), p. 140-149.

"Informações presentes no paxárgrafo, exeto nota 10 , foram obtidas no site do Consulado Geral do Japão no Rio de Janeito, http://www.rio.bremb-japan.go.jp/portuguese/noticias/outubro/out98.htm 